\title{
Apply of traditional cultural symbols into fashion design based on Cross-cultural communication
}

\author{
Yixin Zou ${ }^{1 *}$, Eakachat Joneurairatana ${ }^{2}$ \\ ${ }^{1 *}, 2$ Faculty of Decorative Arts, Silpakorn University, Bangkok 10700, Thailand \\ ${ }^{1 *}$ Fujian Clothing Industry Technology Development Base, Fuzhou, Fujian,350108, China
}

\begin{abstract}
Due to the popularity and importance of cross-cultural communication in our daily life, many countries have carried out various cross-cultural communication activities and researches. However, there is still a big research scope for the study of fashion design based on it. The main purpose of this article is to have a study on the cultural exchange between China and Thailand, with Long ("Dragon" in Chinese) and Naga as case study. The methods in this research can be regarded as the process of "decoding and encoding". Final results are: 1) Extraction of design concepts on Long and Naga based on two times of decoding. 2) A demonstration of the new methodology which can be used for fashion designers to effectively extract cultural code in the background of cultural globalization. 3) It is a case study to do cross discipline research between fashion design with cross-cultural communication.
\end{abstract}

\section{Introduction}

Cross-cultural communication has become a very common phenomenon in the life of contemporary people and society. It involves not only citizens' living standard, but also the global influence of a country, such as national relationship and the role in globalization. Cross-cultural communication or intercultural emphasizes the "cross" and "leapfrogging" between different cultures. Cross-cultural Communication Discipline refers to the activities of communication between individuals, groups or organizations of different cultural backgrounds. However, the research on its disciplines and fashion designs is fairly limited. The existing requirements for cross-cultural communication disciplines and fashion design disciplines have the following problems. On the contrary, the current researches are mostly on functions of clothing and its symbolic meaning. Secondly, most researches on cross-cultural communication based on fashion design are theoretical researches, lacking on-site investigation support. Based on this situation, the researcher will do the research of fashion design in accordance with cross-cultural communication.

\section{Literature review}

\subsection{Cross-cultural communication with fashion design.}

"Fashion" as a none-verbal communication is often used as a way of communication in cross-cultural communication, from which people can feel different cultures and styles from their costumes. Roland Barthes[1] pointed out that the concept of symbols includes signifier and signified. The fabric, color and structure of the clothing belong to both the environmental communication way and the "signifier" in the symbol, while the Signified refers to the conceptual content, the abstract thinking and the expression of emotions etc. Apparel has the most intuitive connection between the signifier and the sign of the symbol compared to the general symbol. Clothes are not only the primary symbol, but also cover the Multi-level symbol system. According to the famous secondary symbol significant system of Roland Barthes, the secondary symbol system is never the final symbol level, and there are even fourth and fifth levels, etc. This is a kind of study of multilevel symbol significant system in the cross-culture study. Paivio[2] proposed the dual-coding theory and coded messages into iogogens and imagines. These two systems will generate a mutual corresponding relation which can improve communication In addition, how to do fashion design based on cross-cultural communication? According to "decoding and encoding" theory by Stuart Hall, the fashion designer is the creator of the apparel product and the transmitter of cultural information. The designers encode the culture by semiotic through the selection and matching of materials, color, pattern and so on. "Decoding" is the audiences' perception of the apparel product, then completes the information delivery process[3]. However, in the process of product design, designers sometimes have inaccurate understanding of cultural codes or rely too much on "personal consciousness", which affects the effective transmission of "code" in cross-cultural communication.

"Corresponding author's email: zouyyxx@163.com 
In this research, the researcher chose China Long ("Dragon" in Chinese) and Thailand Naga (showing in Figure 1) as case study to do the research about fashion design with cross-cultural communication. The core and the essence of culture are people's social psychology and ideology, including people's view of value and life, aesthetic taste, thinking way, religious and faith and their literary and artistic works, especially, the totem worship. The social groups of primitive people mostly took a certain animal or plant as their name, and believed that they were the ancestors of the clans, or related to them by "blood". From the study of their national myths, we can explore the source of the philosophical spirit of a nation.
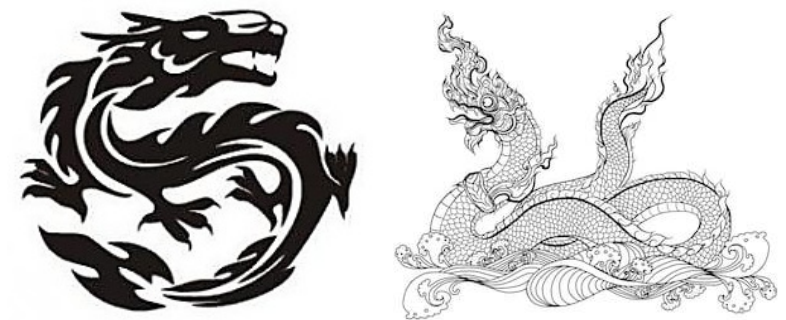

Figure.1 Picture of Long[4] and Naga[5]

\section{Research methodology and process}

Researchers proposed a hypothesis from the discussion and analysis of literature, which explains fashion design as a medium to do harmonious communication in cross-cultural activeness. In addition, "decoding and encoding", Stuart Hall's cultural communication theory, is selected as the main guidance of this study to combine with the fashion design discipline.

The "communication" is a process of "encoding-decoding", that is, a secondary conversion of "symbol -- meaning -- design product" and then "product design -- meaning". If the spreader and audience are in different "language systems", the "encoding-decoding" process can only be realized with the medium of a "translator", who is just the designer in fashion design. However, due to the existence of the "translator", the communication process is extended to two processes of "encoding-decoding", that is, "encoding (The spreader encodes the cultural symbols) - decoding (The designer decodes the cultural symbols) - encoding (The designer re-encode the meaning into the design product) decoding (Stakeholders decode)." In the first process of "encoding-decoding", the cultural symbols are encoded by the spreader and then decoded by the designer; whereas in the second process of "encoding-decoding", the designer re-codes the decoded meaning and spreads it to the stakeholders; this is a re-encoding process. In the process, the designer plays the dual roles, both the recipient of the first communication process and the spreader of the second communication process. The research methods used in this research are shown in Figure 2:

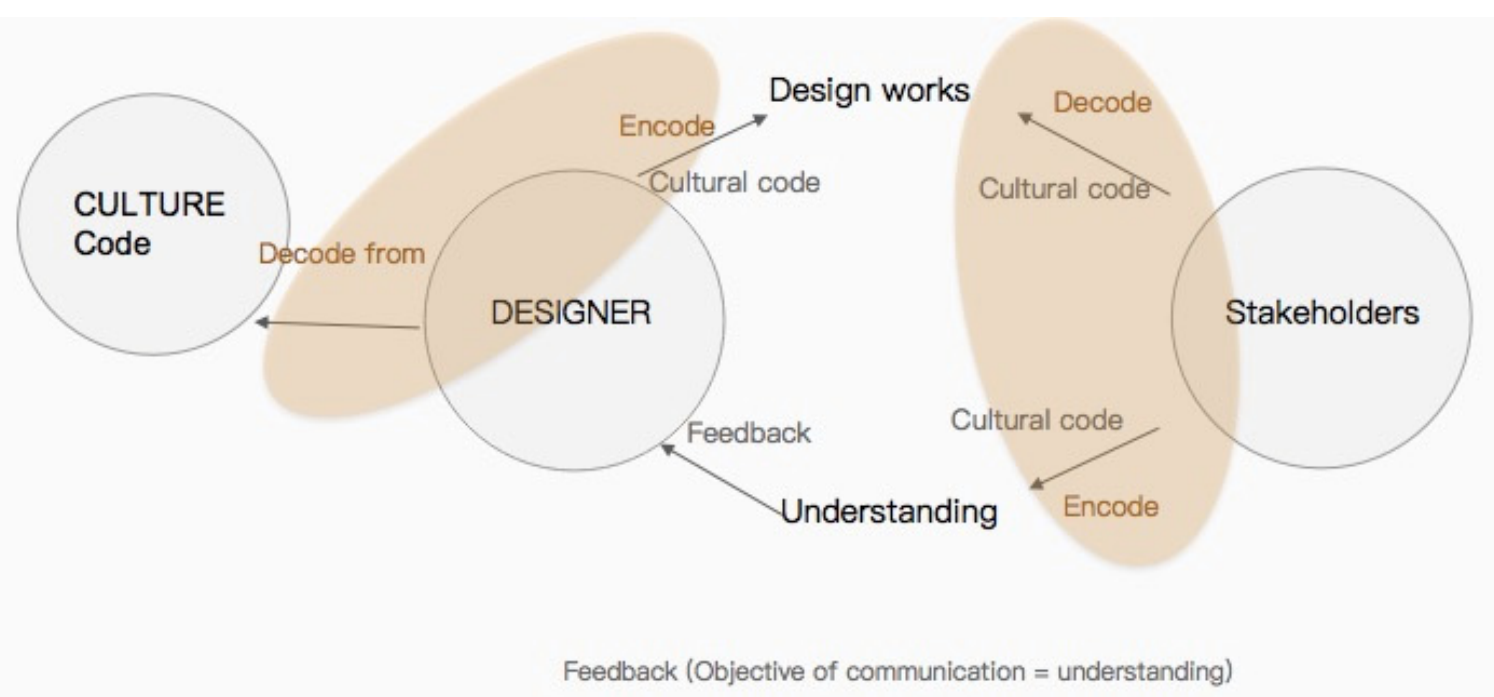

Figure 2. Research methodology (Author's summary)

\section{Design concept extract and samples}

Researchers acquired some "codes" of Long and Naga after did a series of "decoding". The following content is the analysis of "code" and apply in fashion design. With the emergence of a series of problems, such as the energy crisis, environmental degradation and ecological imbalances, people's consumption habits have changed. Environmental protection has become an important concern. Following the concept of "sustainable development", the samples are usually made by recyclable materials.

\subsection{Design concept 1}

Early animal worship and mythological stories were mostly based on human fantasy and imagination to meet human emotional needs. It can be regarded as a combination of art and non-art, which is not only an art form, but leads to philosophy. Undoubtedly, this philosophy is expressed through art in myth, the origin of 
which is based on human's opinion and understanding of themselves, that is, involving the life phenomena in nature. Besides, during this process, people gain a sense of belonging and seek self-protection through totem worship to maintain the inner spiritual source needed for the survival and development of the nation. The worship of Long and Naga can be interpreted as the ancient people's worship of snakes. Before the ancients had a
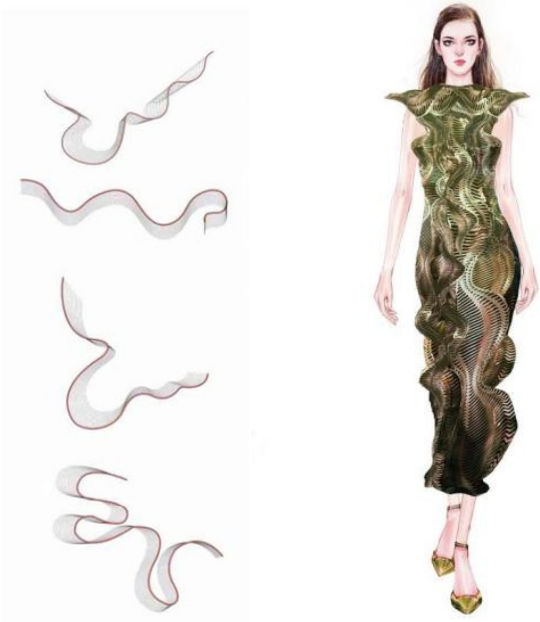

reverence for nature, they placed this affection on animals or plants and endowed them with divinity. This explains why the body lines of the Long and Naga are "S curve line". In addition to nature worship, they also reflect the naked local people. Figure 3 is showing the design process, sketch and experiment sample. The sample material is Tyvek.

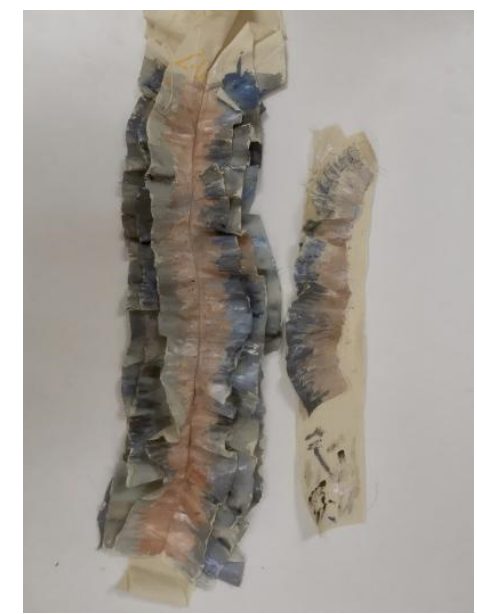

Figure 3. Sketch and Sample for concept 1

\subsection{Design concept 2}

As for the common point of the Myth about LONG and NAGA, they have the ability to control water and rainfall. Snake born the human and tribes. In philosophy, it is even said that snake is the "tree of life", and at the same time, snake is the symbol of water [6]. Water was extremely important to ancient humans, and it gave birth to life and civilization. In Thailand story, Naga is the symbol of "Mekong River". In China Story, they are the King of Ocean long living in the sea. [7]. This is because in the past, people were living among the nature, where they were surrounded by various dangers. Also, they could not yet understand the natural phenomenon such as thunderstorm, earthquake, or some other natural disasters. Therefore, the "Supernatural" and "Animism" emerged in order to comfort them from fear. They started praying, worshiping, and sacrificing some spirits in order to get some protection and abundance from what they believe. Interestingly, "Snakes" which were known as the most dangerous species due to their abilities were not only the deadly poisoned but also the silenced movement that could go everywhere from above ground or underground into the water or even in the air.

The design sketch combines rainfall with scales of Long and Naga. The transparent PVC overcoat shows the deity and mystery of the LONG and NAGA. The whole clothes show that LONG and NAGA link with life and water. The manufacturing approach of sample 1(Figure.4) is: Heat the organza yarn to make it wrinkle, then use hot pressing method to make it adhere to the foil and Tyvek. In this step, heating the Tyvek by different temperatures will cause the different wrinkles.
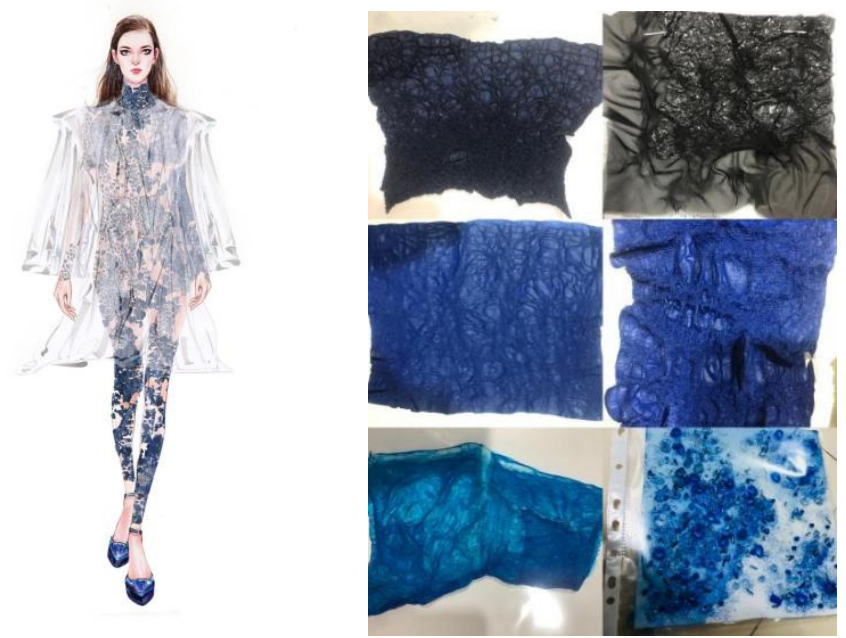

Figure 4. Design sketch and samples for concept 2 


\section{Conclusion}

The outcome of this research will be presented in the form of clothing, extraction of research example used in costume design to do further cultural integration. Meanwhile, a fashion will be held to show the story about Long and Naga, and further research about audiences' ideas will be carried out as well This research will help the subjects to be more fashionable and then combine with modern technology in order to spread the idea to more people. In addition, different costume design techniques are also used to show the design under cross-cultural background, such as the application of fabric reflecting Naga and Long's physical characteristics. New image and cultural context of Thai Naga and Chinese Long will be good examples about combination of cross-cultural communication with modern fashion design. A mature fashion design research methodology can help fashion designers use clothing to deliver hidden culture and meet the aesthetic needs of the audience. This research is a new paradigm that combines theory, practice and methodology exploration. It not only proposes new models, but also reflects them in the research process.

\section{Acknowledgments}

The authors acknowledge the 2019 Open Project Program of Fujian Clothing Industry Technology Development Base, Minjiang University, China (No. MJXY-KF-201909).

\section{References}

1. Chandler, D. (2017) Semiotics: the basics. Taylor \& Francis.

2. Sadoski, M., \& Paivio, A. (2013) Imagery and text: A dual coding theory of reading and writing. Routledge.

3. Hall, S. (2010) Encoding, decoding 1. Social Theory: Power and identity in the global era,2, 569-599.

4. Cxtuku. (2013) Long CDR. http://www.cxtuku.com/pic_844127.html

5. Nipatsara Bureepia. (2018) https://www.shutterstock.com/

6. Macauley, D. (2010) Elemental philosophy: Earth, air, fire, and water as environmental ideas. Suny Press.

7. HengWei Zhang, PinPin Xie. (2015) The modern spirit embodied in Long culture. Sports Research and Education: 2015; Volume 30. 